УДК 78.01+78.08/78.071.1

\title{
E. Стрильчук
}

\section{ВЕКТОРЫ МУЗЫКАЛЬНОГО ВРЕМЕНИ В ПРОИЗВЕДЕНИЯХ О. МЕССИАНА}

Музыкальное время детерминируется отношением музыкального звучания к смыслу, а смысла - к звучащей форме музыки...

А. Самойленко

В статье раскрываются различные способы работы О. Мессиана с категорией музыкального времени, проявленные на различных композииионных уровнях. Единый эстетический принцип - стремление преодоления времен и достижения вечности - можно увидеть в произведениях разных периодов творчества. Тексты этих произведений выявляют две центральные музыкальные эмблемы композитора: пение птии и эмблему любви.

Ключевые слова: «чистое» время, структурированное время, звучащее и незвучащее время, музыкальная эмблема.

В XX веке понятие/категория времени рассматривалась с большим вниманием как в точных науках (в частности, в физике), так и в гуманитарных (в частности, в философии). Из всего разнообразия теорий и концепций внимание в данной статье обращено к пониманию категории времени Анри Бергсоном, терминами которого пользуется Оливье Мессиан. При этом Мессиан не стремится воссоздать/воплотить в своей музыке философскую концепцию Бергсона. Он лишь использует некоторые понятия и позиции для того, чтобы разъяснить своё понимание времени. В одном из своих поздних трудов - «Длительность и одновременность» (1922) - Бергсон задался целью соотнести свою концепцию длительности с категорией времени в теории относительности А. Эйнштейна, а также разграничить категории времени и пространства [4].

В человеческом обиходе время выполняет две функции: служит для измерения длительности процессов и позволяет устанавливать порядок событий. Возможность такого использования предопределена двойственной природой феномена времени [3]. Для выражения своего понимания времени Бергсон пользуется парой категорий квантитативного и квалитативного времени, именуя их соответственно как время-порядок и время-дление (temps и duree) [3; 2, с. 9]. В категории времени-порядка (temps - с фр. переводится как «темп» или «ритм») «время как бы останавливается, элиминируется, - по мысли Бергсона, - превращается в пространство и число» [2, с. 9]. Время-

(C) Стрильчук Е., 2015 
дление (duree - с фр. переводится как «чистая длительность» ${ }^{1}$ ) единое, неделимое, «чистое» время, лишённое каких бы то ни было пространственных характеристик, противопоставлено «застывшему времени» физики («поскольку физическое время описывает малые интервалы, которые, по сути, одинаковы») [1] и соотносится с музыкальным искусством [6, с. 62-63]. Данное высказывание Бергсона позволеят М. Аркадьеву приравнивать «бергсонианское время» К музыкальному времени-энергии как пульсационно-экспрессивному континууму [2]. В то же время у Бергсона можно найти и более точные характеристики времени-дления, что даёт возможность относить к последнему не всё музыкальное искусство в целом и не единое музыкальное время как таковое, а лишь отдельные его фрагменты.

Опираясь на главенство категории времени в музыкальном искусстве и понятие музыкального времени, которое не ограничивается непосредственным звучанием музыкального произведения, можно говорить о музыкальном времени как о некоем целостном единстве «звучащей» и «незвучащей» временной материи (музыкальной ткани). Рассматривая «звучащую» и «незвучащую» категории в комплексе с понятиями чистого и структурированного времени, вектор этой пары категорий можно наложить на вектор вышеуказанной пары: «чистое время - структурированное время» (время-дление и время-порядок по Бергсону) [3]. Наложение этих категорий позволит лучше разобраться в принципах проявления категории времени в музыке Мессиана.

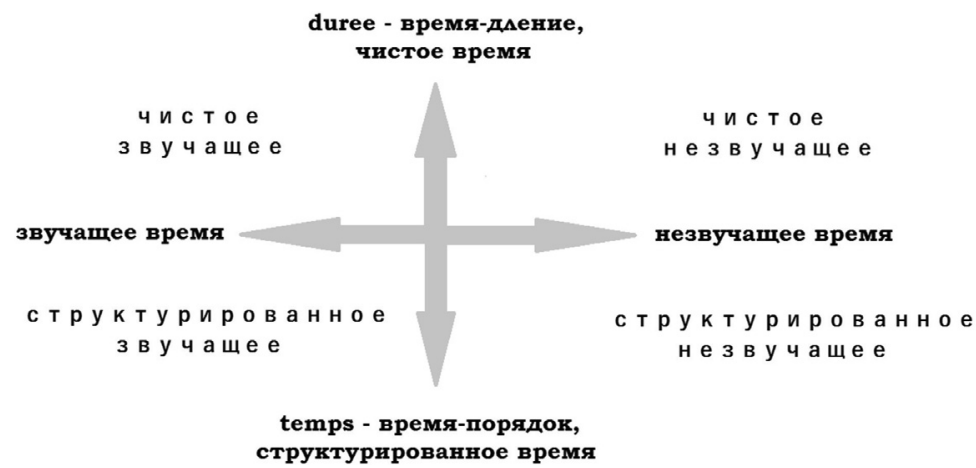

1 В данном случае слово «длительность» не следует понимать как музыкальный термин. О проблемах перевода говорит М. Аркадьев, делая следующие ссылки: Трубников Н. Н. Время человеческого бытия. М., 1987. С. 145; Притыкина О. И. Музыкальное время: понятие и явление // Пространство и время в искусстве : межвузовский сборник научных трудов. - Л., 1988. - С. 78-80. 
Среди четырёх смоделированных пар, призванных, так или иначе, характеризовать музыкальное время, всё же не в каждой музыкальное звучание находит своё непосредственное воплощение. Исключение составляет «чистое незвучащее» время. Чистое незвучащее - это чистое «звучание» времени как такового, вне звучащих хронотопов, это звучание тишины или звучание космоса, это область принципиально недоступного человеку, «идеального незвучащего временного пульсационного континуума». И, следовательно, такое время выходит (входит/уходит) в сферу категорий, связанных с понятием Вечности. Не имея возможности предметно, музыкально к нему «прикоснуться», Мессиан, тем не менее, стремится к нему (идёт в этом направлении), о чём «сообщает» посредством программности своих произведений.

В музыке чистое время (duree) проявлено в звучащем виде, при этом лишённом каких-либо пространственных характеристик. Чистое звучащее время музыкального произведения становится непрерывным пульсирующим хроно-актикуляционным континуумом. По словам Мессиана, «чтобы уловить явление чистой длительности, в музыке не должно быть никаких повторов, симметрий, ничего такого, что позволило бы нашему сознанию считать и сопоставлять $<\ldots>$ следовательно, чистым выражением времени становится «гетерофония», «гетерохрония», «гетерохромия», «гетеродинамия» и, наконец, «гетерохронодинамия» (цитата из т. 3 «Трактата о ритме, цвете и орнитологии») [7].

То, что Мессиан именует «гетерохронодинамией», Бергсон называет «чистой разнородностью», как в следуюшем цитируемом высказывании: «Чистая длительность вполне могла бы быть только последовательностью качественных изменений, вместе сливающихся, взаимопроникающих, без ясных очертаний, без стремления к внеположенности по отношению друг к другу, без всякого родства с идеей числа: это была бы чистая разнородность». Из чего Мессиан делает вывод: «значит, чтобы уловить явление чистой длительности, в музыке не должно быть никаких повторов, симметрий, ничего, что позволило бы нашему сознанию считать и сопоставлять» [7]. Но повторы, симметрии и любые числовые проявления возможны, если «гетеро» заменить на «моно», и в таком случае «чистое звучащее время» будет воплощаться через «чистую однородность». Так появляется ещё одна пара категорий: разнородное и однородное время. Во избежание нагромождения (смыслов), эта пара накладывается на первоначально противопоставленные чистое и структурированное время. 


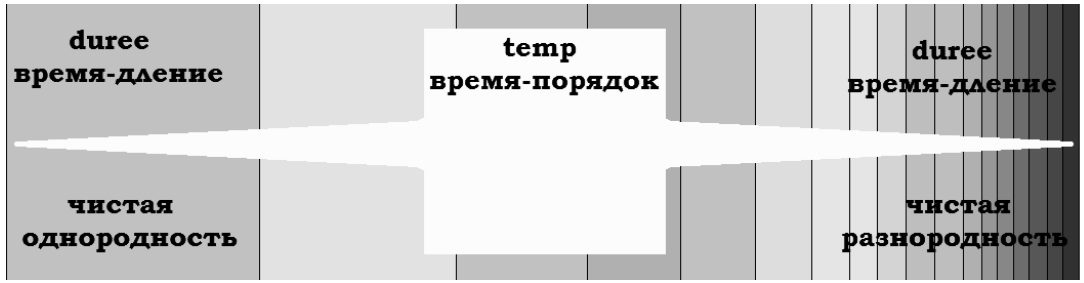

Взаимозаменяемые разнородное и однородное время являются двумя противоположными (и крайними) вариантами одного процесса дробления, структурированности времени: в первом случае («чистой разнородности») оно бесконечно делится, что не воспринимается слухом, во втором же случае оно не делится вовсе.

«Чистая разнородность» характеризуется ритмической и метрической свободой, преобладанием мелких длительностей, в интонационном плане - максимальным разнообразием, однако тембру, динамике и артикуляции внимания уделяется меньше. Формообразующие элементы здесь также отсутствуют. Музыкальная ткань «чистой разнородности» представляет собой чистое «воспроизведение» пения птиц. Кроме циклов и отдельных частей произведений, целенаправленно/преднамеренно посвящённых птицам, не менее ярким примером в данном случае можно обозначить шестую часть семичастного симфонического цикла «Хронохромии» (1960) - эпод ${ }^{1}$. В данном случае эпод представляет собой контрапункт 18 струнных инструментов или 18 сольных голосов, переплетающихся в «хаосе», как метко (симптоматично) указал Мессиан на отсутствие структурирования времени. К слову, это также единственная часть цикла, на которую не распространён ритмический пермутационный цикл (чистое воплощение структурности (идеи числа) и порядка).

«Чистая однородность» характеризуется однотипной инструментовкой и сходной фактурой: в большинстве случаев это унисон скрипок с волнами Мартено; движением мелодии в хоральном изложении без какого-либо контрапункта на гармонической педали, тихой динамикой, медленным темпом (Treslent, Tresmodere, trestendre, Moderelourd, Unpeulent). Здесь презентуется абсолютная континуальность, что выражено в отсутствии пауз, господстве легато и крупных длительностей. Ключом к раскрытию содержания «чистой однород-

1 Эподом в античной поэзии называли заключительную строфу трёхчастной хоровой формы, выполняющей функцию припева (строфа-антистрофа-эпод). 
ности» стала авторская самоповторность, которая и позволила объединить этот тематический материал в самостоятельный хронотоп эмблему любви. Эта тема является явным продолжением тем любви «Турангалилы симфонии» (1948), где II и VI части подобного склада носят названия «Песнь любви I» и «Сад сна любви». Также эта эмблема проявляется в оркестровых циклах «Из ущелий к звездам» (1974, в VIII части «Воскресшие и песнь звезды Альдебаран»), «Прозрения загробной жизни» (1992, V - «Пребывая в любви», XI - «Христос, райский свет»). В драматургическом плане эмблема любви играет важную роль, появляясь в кульминационных и итоговых (завершающих) частях/разделах формы.

Находясь в области чистого времени, эмблема любви и символический образ птиц, будучи опорными в поэтике композитора, указывают на тот смысл, который призван не быть раскрытым в полной мере, до конца, и который граничит с чистым незвучащим временем. Ведь он находится там, где времени уже нет, где оно «исчезает». Время исчезает при беспредельном увеличении единиц измерения одной из категорий (длительности или порядка) и, как следствие, беспредельном уменьшении единиц измерения другой [3]. На примере однородности-разнородности можно проследить тенденцию к увеличению длительности одного хронотопа (эмблемы любви) и к упорядочиванию весьма коротких других хронотопов (пения птиц).

Итак, время-дление у Мессиана - это чистое, «длящееся» время. Данное понимание времени, «временящаяся длительность», говоря словами Мессиана, тем самым согласуясь с неизмеримостью времени как Вечности, в то же время он говорит, что чистая длительность - это чувство континуальности жизни, её непосредственного протекания в настоящем, которое предстаёт исключительно субъективным явлением.

А стоит только измерить время, структурировать и сосчитать его, как оно сразу приобретает характеристики пространства - это время-порядок. Как такое понимание времени может соотноситься с временем музыкальным?

Принцип повторности как важный приём композиторской техники и идея числа (по Бергсону), имеющий практическое воплощение и символическое значение в произведениях Мессиана, являются основными способами структурирования музыкальной ткани. Структурированное звучащее время ярче всего проявляется в категории диссонанс-экспрессии, пользуясь термином В. Холоповой, в поздних и 
ранних произведениях Мессиана, в которых можно усмотреть неоклассицистские черты («Фуга» (1928), «Тема с вариациями» (1932), «Вокализ» (1935), «Фантазия» (1933), «Рондо» (1943), «Улыбка» (1989), «Пьеса для фортепиано и струнного квартета» (1991), «Концерт для четырёх солистов» (1990-91). Диссонанс-экспрессия проявляется в дроблении, дискретности музыкального звучания с помощью очевидных выразительных приёмов: коротких интонационных мотивов, частой смены фактуры, оркестровки, динамики, темпоритма, артикуляции. Эта сфера выступает в качестве антиномичной пары к консонанс-экспрессии, которая тяготеет к «чистому времени». Проявление неоклассицизма - это частный случай использования дискретности, сосредоточенной в области формообразующих средств. K нему композитор прибегает сознательно, отдавая дань традиции (о чём говорится в посвящениях к некоторым поздним произведениям).

Использование Мессианом числа как инструмента структурирования времени для слухового восприятия не столь явно и очевидно, но имеет важное значение для целостного понимания концепции его отдельных произведений. Неоднократно он высказывался о своей любви к числам, что выразилось в сложных числовых закономерностях, образующих пермутационный цикл в «Хронохромиях», «Семь хайку» (1962), «Цветах Града Небесного» (1963). Однако использование числовых методов у Мессиана основным композиционным принципом не является и распространяется только на ритмические структуры. В структуре и формообразовании произведений на протяжении всего творческого пути можно проследить символику и эмблематику числа [5], что неоднократно отмечено отечественными и зарубежными музыковедами (например, числа 3 в «Трёх маленьких литургиях» (1944), 7 в «Семь хайку», 8 в «Квартете на конец времени» (1941) и др.).

Следует сказать и о роли пауз в дробности музыкального материала, но их значение гораздо шире/глубже. Паузы представляют собой отдельную область структурированного незвучащего времени. О своём «видении» пауз композитор высказался на страницах «Трактата о ритме, цвете и орнитологии». Он выделяет три знакомых нам вида пауз: 1) паузы продолжающие (silencedeprolongation), 2) паузы приготавливающие (silencedepreparation), 3) паузы-пустоты или паузыдыры (silencevide) [7]. Последний вид пауз впервые в творчестве Мессиана встречается в «Хронохромиях». Впоследствии Мессиан не раз будет обращаться к подобным паузам. В частности, не имеющая, на первый взгляд, прямых ссылок на идею воплощения времени, парти- 
тура оркестрового цикла «Из ущелий к звёздам» содержит в себе ряд подобных примеров. Характеризуя эти паузы, Т. Цареградская использует такие слова: «разрыв», «ничто», «вакуум». Структурное расположение этих пауз - на стыке двух самостоятельных музыкальных тем/фрагментов. Самостоятельность этих пауз он подчёркивает индивидуальными ремарками, сопровождающими темповые указания. Именно исходя из специфики темповых указаний, Т. Цареградская строит своё предположение о том, что такие паузы Мессиана являются «ходами» в иное время. С ней можно согласиться, так как, кроме закономерно выписанного темпа, в партитуре указан и необходимый инструментальный состав, «исполняющий» такую паузу, отличный от состава инструментов предыдущего и последующего фрагментов.

Если сфера чистого времени приводит к категории смысла, то сфера структурированного времени указывает на форму и знаковые способы её проявления. Особую знаковую ответственность Мессиан возлагает на тембр.

Экспериментируя с тембрами, Мессиан обращается с ними как с самостоятельными персонажами, поручая каждому свою собственную партию, наделяя её особой функцией (смыслом, концепцией). Тембрами Мессиан пользуется как речевой формулой, музыкальной лексемой, родственной словесному высказыванию; тембры «говорят» И «извещают»: выполняя сигнальные функции, заимствованные из культовых обрядов; проявляя и свои устойчивые (в европейской музыке) семантические функции; тембры выполняют формообразующую функцию и являются одним из трёх средств передачи цвета, окрашивания времени (два других средства - это мелодический контрапункт и гармония).

Из бесед О. Мессиана с К. Самюэлем: «Нужно, если осмелюсь так сказать, чтобы медные инструменты «играли красный цвет», деревянные духовые «играли голубой» и так далее...». Это цитата из диалога об оркестровом цикле «Цвета Града Небесного» ${ }^{1}$, в партитуре которого указаны данные цвета в качестве ремарок. На примере этого цикла можно увидеть максимально полное воплощение порядка в музыке, где время застывает и останавливается, превращаясь в цвет.

С цветом, воплощённым в пространстве, и временем Мессиан играет/манипулирует и в обратном направлении, в чем можно убе-

\footnotetext{
1 Здесь композитор апеллирует к словам св. Иоанна: «Фундамент стены Святого Града украшен всеми драгоценными камнями: яшмой, сапфирами, халцедонами, изумрудами, сардониксами, сердоликами, хризолитами, бериллами, топазами, хризопразами, гиацинтами, аметистами», обращая внимание на присутствие всех цветов радуги.
} 
диться на примере оперы «Святой Франциск Ассизский». В пространственном плане оперы (в рекомендациях к оформлению костюмов персонажей) он разворачивает во времени (и пространстве) двухмерные картины различных художников эпохи Возрождения, вдохновленных традицией изображения Франциска, Ангела, Прокажённого. Этот его эксперимент напоминает модель развёрнутого земного времени относительно существующего вне времени космоса. Двухмерный «картинный» визуальный ряд, лежащий в основе оперы, приводит к восприятию музыки не как процессуального явления, а как планомерного озвучивания вневременных пространственных картин, как пояснение и чувственное переживание (по)данных событий. Событий, связанных с жизнью Святого Франциска и чудесами, происходящими с ним.

Данная опера есть пример реализации различных временных векторов, как в структурно-композиционном, так и в смысловом планах, поскольку в основе её - две главные/доминирующие, эмблематически обозначенные идеи композитора: пение птиц и ноэма любви. Их объединяющим условием становится то, что, какое бы направление ни имели векторы музыкального времени в произведениях Мессиана, они всегда направлены в Вечность.

\section{СПИСОК ЛИТЕРАТУРЫ}

1. Аристов В. В. Построение реляционной статистической теории пространства-времени и физическое взаимодействие / В. В. Аристов // На пути к пониманию феномена времени. Ч. 3 / [ред. А. П. Левич]. - М.: ПрогрессТрадиция, 2009. - С. 176-182.

2. Аркадьев М. А. Временные структуры новоевропейской музыки. Опыт феноменологического исследования / М. А. Аркадьев. - М.: Библос, 1993. $168 \mathrm{c}$.

3. Арманд А. Д. Дуализм времени / А. Д. Арманд // На пути к пониманию феномена времени. Ч. 3 / [ред. А. П. Левич]. - М.: Прогресс-Традиция, 2009. - C. $460-478$.

4. Бергсон А. Длительность и одновременность / А. Бергсон; пер. с фр. А. А. Франковского. - Петербург: ACADEMIA, 1923. - 154 с.

5. Bruhn S. Messiaen's interpretations of holiness and Trinity: echoes of medieval theology in the oratorio, organ meditations, and opera / S. Bruhn. - Siglind Bruhn, 2008. - $229 \mathrm{p}$.

6. Орлов Г. Древо музыки / Г. Орлов. - Вашингтон; Санкт-Петербург: Советский композитор, 1992. - 408 с.

7. Цареградская Т. В. Время и ритм в творчестве Оливье Мессиана / Т. В. Цареградская. - М.: Классика-XXI, 2002. - 376 с. 
Стрильчук О. Вектори музичного часу в творах О. Мессіана. У статті розкриваються різні засоби роботи О. Мессіана з категорією музичного часу, проявлені на різних композиційних рівнях. Сдиний естетичний принцип прагнення подолання часу і досягнення вічності - можна побачити в творах різних періодів творчості. Тексти цих творів виявляють дві центральні музичні емблеми композитора: спів птахів і емблему любові.

Ключові слова: «чистий» час, структурований час, час який звучить, час, який не звучить, музична емблема.

Strilchuk O. Vectors musical time in the works of Olivier Messiaen. The article describes the different ways to work with O. Messiaen's musical time categories, displayed in various compositional levels. Uniform aesthetic principle - the desire to overcome the time and achieve eternity - can be seen in the works of different periods of creativity. The texts of these works reveal two central musical composer emblems: the birds singing and the emblem of love.

Keywords: the «pure» time, structured time, sounding and not sounding time, musical emblem.

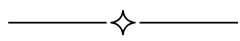

УДК $78.03+785$

\title{
I. Форманюк
}

\section{П’ЕСИ ДЛЯ ДОМРИ-СОЛО: ФІЛОСОФСЬКО-ЕСТЕТИЧНІ ТА МУЗИЧНО- ТЕХНОЛОГІЧНІ ПІДСТАВИ МІНІАТЮРИЗАЦІЇ}

\begin{abstract}
Стаття присвячена з'ясуванню ролі і значення сольної мініатюри в процесі еволюції концертного домрового репертуару, виявленню актуальних фактурних форм та ідейно-образних параметрів цих творів, а також виконавських особливостей їх концертної подачі. Підкреслюються оригінальність та специфіка втілення у жанрі мініатюри «тихих», камерних звучностей домрового звуку, у тому числі в сонорно-домровому комплексі.

Ключові слова: домра, домрова музика, домра-соло, мініатюра, мініатюризація.
\end{abstract}

В останнє десятиріччя XX - на початку XXI століття в концертному (і навчальному) домровому репертуарі все частіше зустрічаються твори для домри-соло. Серед них провідна роль, безперечно, належить мініатюрі. Ті відомі нам циклічні композиції, які створені для цього інструменту без супроводу, «зібрані» в цикли таких мініатюр («П’ять каприсів» А. Циганкова, «Сім характерних п’єс» Б. Міхеева, 